\title{
THE TIMING OF MITOSIS AND MEIOSIS IN ALLIUM ASCALONICUM: A PROBLEM OF DIFFERENTIATION
}

\author{
C. D. DARLINGTON and ASHRAFUL HAQUE \\ Botany Department, University of Oxford
}

Received 16.vi.54

\section{THE ABNORMAL PLANT}

Together with a fertile crop of onions raised at Benares, one plant was seen to set no seed in the glasshouse. The bulb was split and all the sets flowered in England. Their anthers, however, never burst. When ripe they turned green instead of yellow. Sections cut by the freezing microtome showed much chlorophyll in the anther wall. Within the anther the pollen grains dried up and died after their first mitosis. The development of the embryo sac was normal. With foreign pollen, moreover, the plants set seed which germinated well.

Thus the sterility of our plant, or clone as it now is, is due to failure of the pollen to develop to maturity. This decisive and total disability is preceded, however, by certain small and sporadic errors much earlier in the development of the pollen-forming tissue. From a study of these errors there came to light an instructive group or syndrome of defects whose origin we have attempted to trace.

\section{METHODS}

Anthers and root tips were fixed in fresh acetic-alcohol $(1: 3)$ for ten minutes and stored overnight in 95 per cent. alcohol before staining by the Feulgen method (La Cour, 1947). Equally good results were also obtained by fixing anthers overnight in acetic-alcohol with a trace of ferric chloride followed by staining in weak acetocarmine (P. T. Thomas, unpub.).

For studying their development the ovules and anthers were fixed in La Cour's $2 \mathrm{BE}$ after a short treatment with Carnoy's fluid. The material was embedded and sections cut at $10-14 \mu$ were stained by the Feulgen method. Light green was used as a counterstain for the cytoplasm and the cell walls.

\section{MEIOSIS IN THE ANTHERS}

The chromosome complement as seen in the root tips consists as normally in Allium ascalonicum of eight pairs of chromosomes of which two pairs-one longer than the other-had median and the rest sub-median centromeres. The latter class included a satellited pair carrying the nucleolar organiser (plate, fig. I).

In the anthers of most of the flowers from different inflorescences meiosis is regular. In the remainder, about one-third, up to 20 per cent. of the pollen mother cells in every anther show a group of meiotic abnormalities including asynapsis. 


\section{(i) Chromosome breakage}

Pre-meiotic cells.-In order to trace the causes of asynapsis to an earlier origin we examined the mitoses before meiosis. Sections from anthers at the pre-meiotic mitosis reveal zones of abnormal cells. The zones are always central and at the two ends of the lobes. Sometimes one zone is abnormal, rarely both. The abnormality consists in a delay in mitotic phase correlated with a larger size of cells and breakage of the chromosomes (plate, fig. 2). Evidently these cells have continued growing while the normal cells have stopped or slowed

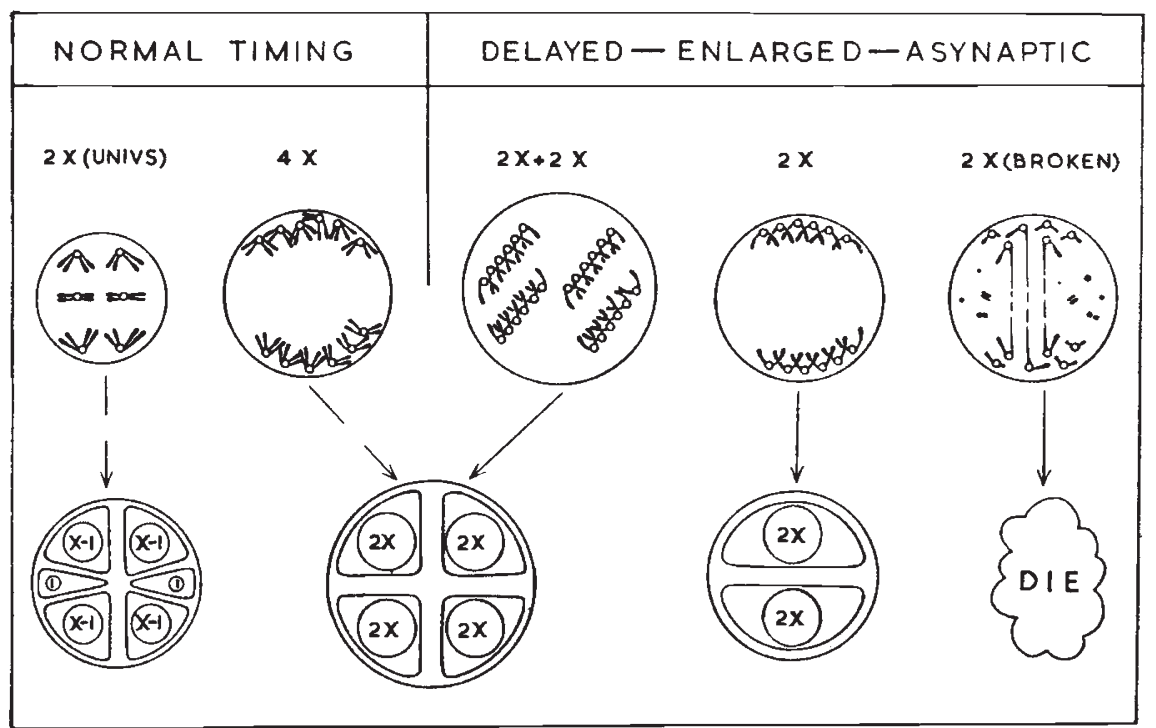

Fig. 1.-Diagram showing the chief courses of development in the two series with normal and delayed timing. The haploid set of eight is represented by three chromosomes.

Above : first anaphase, which in the asynaptic series is the only anaphase.

Below : the products of meiosis.

Note that tetraploid cells and nuclei occur in both series. Tetraploid nuclei with pairing and tetraploid cells (with two diploid nuclei) without pairing, both give four diploid pollen grains.

down their growth and entered mitosis. And the delay in mitosis (or the continued growth) is associated with a breakdown in chromosome development leading to breakage during the preceding resting stage.

All this happens two resting stages before meiosis. During the resting stage immediately before meiosis there are cells with micronuclei evidently derived from this fragmentation. They seem to disintegrate rapidly, however, for they are never seen among cells entering meiosis. Multinucleate cells (to which we shall return later) are found at this stage but they are either cells such as would be derived from failure of wall formation or from split spindles. They arise from spindle errors and not from chromosome errors. 
Pollen mother cells.-The damaged pre-meiotic cells having disappeared, a second wave of abnormality strikes the meiotic cells. Presumably, although our squashes do not show it, the sensitive zones are the same zones as those affected earlier but in previously unaffected lobes. Again the affected cells are delayed in their development. The delay varies and during prophase is reduced. But again it is always associated with a larger size of the cells (plate, fig. 8). Again it seems that the delayed cells go on growing while those entering prophase cease growing or grow more slowly (fig. I).

The delayed cells mostly show breakage, usually heavy breakage, at the diplotene stage (plate, figs. 4, 5). At first metaphase the cells with breakage reveal their abnormal conditions sometimes by stickiness of the chromosomes and sometimes by incomplete spiralisation, both of them typical of X-ray effects (plate, fig. 1o). These combined with the breakage usually make analysis impossible (plate, fig. 7). Minute fragments, dicentrics, rings and sister reunions seen at first metaphase indicate that breaks are all of $\mathrm{B}^{\prime \prime}$ type and have taken place before the end of pachytene. These breaks should be followed by reunions of chromosomes, or failing these, by sister reunions of chromatids. A preponderance of the results of sister reunion is noticed at anaphase (plate, fig. 9). This indicates that ordinary reunion, which precedes sister reunion, has been prevented, probably because the breakage takes place during pachytene when free movement is excluded.

Breakage in the delayed cells is not, however, invariable. Their invariable property is a greater or less degree of asynapsis. Thus the same abnormality leads to asynapsis and breakage but breakage must be supposed to demand a greater departure from normal.

\section{(ii) Asynapsis}

The asynapsis is of the maize type. At pachytene pairing is complete; but by early diplotene a striking change has taken place. The points where the two chromosomes of each bivalent would normally cross over can then be seen to be simple coilings : chiasmata are absent (plate, fig. 4). This becomes even clearer at diakinesis as the coiling partly undoes itself (plate, fig. 5). By first metaphase, when the chromosomes have reached maximum contraction, the univalents have invariably become free and lie parallel.

In the anthers of our clone there is a sharp cleavage between the normally and the abnormally developing types of cell, just as earlier there is a sharp demarcation between normal and abnormal zones. The majority of the abnormal cells are completely asynaptic (plate, fig. 6). Only a few show numbers of bivalents varying up to four.

In the pollen mitosis is usually normal. Pollen grains are seen with varying numbers of micronuclei carried over from the breakage of meiosis (plate, fig. 18) but these never divide. Only seldom are 
mitoses seen with fragments (plate, fig. I6) and still more rarely with reunions (plate, fig. 17). We see again, therefore, that the abnormal cells derived from breakage and asynapsis are eliminated between mitoses : natural selection takes effect.

\section{(iii) Polyploidy}

In our Allium clone the commonest method of giving rise to unreduced or diploid pollen grains is the substitution of a single division of unpaired chromosomes for the two meiotic divisions. Several other methods, however, are seen operating :

Spindle failure.-Occasionally at pre-meiotic mitosis the spindle mechanism totally fails. As a result the affected cells enter meiosis with a tetraploid complement. They are easily distinguished from the diploids at the pachytene stage (plate, fig. 3). At first metaphase, 16 bivalents can be seen and 16 chromosomes in each cell of the dyad at second metaphase (plate, fig. II). At the end of meiosis tetrads of diploid pollen grains are formed.

Failure of wall formation.-In other cases the spindle at pre-meiotic mitosis fails only in regard to wall formation. This is evident from cells which enter meiosis with two diploid nuclei in each (plate, fig. 3). Such cells seem to give rise to diploid pollen grains in the following ways :

(i) When chiasmata are formed the 16 bivalents, 8 from each nucleus, are arranged on a common plate at the first metaphase. The rest of meiosis is, no doubt, completed in the normal way to give tetrads of diploid pollen grains.*

(ii) When no chiasmata are formed, that is, with asynapsis. The univalents, 16 from each nucleus, are arranged on two distinct metaphase plates. They will divide once to give four diploid pollen grains. In the binucleate pollen mother cells the stages of division in the two nuclei are always synchronised.

\section{(iv) Nucleolar microcytes}

In the normal series of cells a common feature is the occurrence of two univalents at first metaphase. While the bivalents divide and their halves pass to the opposite poles, these univalents lag near the equator without dividing. They may or may not be included in one or both of the anaphase chromosome groups. As a result the second division cells may have seven, eight or nine chromosomes and between them there may be one or two single chromosomes. These form one or two separate microcytes, cut off near the equator of the first division (plate, fig. 12).

* A parallel situation occurs in Tradescantia paludosa. Here binucleate pollen grains are formed owing to failure of wall formation at the end of second meiotic division. But the metaphase chromosomes fuse to give a single plate in the first pollen mitosis, which yields diploid generative and tube nuclei (Haque, r953). 
The microcytes are of interest because often their nuclei containing single chromosomes are seen to divide (plate, fig. I2). At the end of meiosis the microcytes therefore show one or two small nuclei in each depending on whether they have divided or not (plate, figs. I3, 14, 15).

The microcytes at the end of the first or during the course of the second division possess their own cytoplasm and a thin wall. Thus they are supernumerary separate cells with very defective nuclei in comparison with the two major cells of the dyad or four cells of the tetrad. Nevertheless the nuclei of the microcytes divide and they are always synchronised with the nuclei of the two major cells. Such a division has also been described in polyploid Hyacinthus, where the illustrations show the same synchronisation (Darlington, I929). This is an example of co-operation between thin-walled cells in some sort of communication : the complete nucleus of one helps the incomplete nucleus of the other to undergo mitosis. In the absence of this cooperation the incomplete nucleus would not be expected to divide (Barber, I94I ; Haque, 1953).

The two chromosomes whose occasional failure of pairing leads them into microcyte formation seem to be always the two nucleolar chromosomes of the complement. At second anaphase their satellites show very clearly. They can then either be seen in the microcyte or missed from one or both the cells of the dyad.

Nucleoli appear not only in the microcytes of a tetrad but also in all the four major cells. Thus, as McClintock (1934) found in maize, in the absence of a specific nucleolus-organising chromosome its function is undertaken by some other chromosome or by all the chromosomes of the complement.

On rare occasions tetrads are seen with more than two microcytes. In an extreme case as many as eight microcytes have been seen, but in these none of the micronuclei ever divide. Evidently chromosomes other than the nucleolar one may also exceptionally fail to pair. Some second meta-anaphase figures were in fact seen where io and 6 , or I I and 5, chromosomes constituted the two plates. But only those solitary chromosomes with the organiser form temporarily viable supernumerary cells.

Two questions now arise. (I) Why have the nucleolar chromosomes a special propensity for failing to pair or form chiasmata at prophase of meiosis? (2) Why have they a special capacity for forming microcytes which can undergo an independent but synchronised second division?

The failure of chiasma-formation, it would seem, must be related to the delay in pachytene pairing noted in the nucleolar chromosomes of Fritillaria (Darlington, I935). The viable microcytes must be related to those seen in Hyacinthus. It is not known whether the chromosomes forming these separate cells and nuclei in Hyacinthus were nucleolar. But McLeish's discovery (1954) that fragments 
containing the nucleolar organiser in Vicia faba can form viable micronuclei while non-nucleolar fragments at once die makes this probable. In the behaviour of nucleolar microcytes we thus see the consequences of mechanical and physiological properties of the nucleolar organiser which are quite unrelated in cause but happen to reveal themselves in a convenient order for observation.

\section{THE PROBLEM OF DIFFERENTIATION}

In the normal development of the anther in flowering plants there is a differentiation between tapetal and sporogenous tissue. But within the sporogenous tissue all differentiation is suppressed until after meiosis. It then occurs only between genetically identical cells within the several pollen grains. Differences at the same time arise between the pollen grains but these are differences of life and death. They should not (in our opinion) be ascribed to differentiation in a strict sense, for they are due to genetic differences between individuals. They arise from genetic segregation at meiosis as Barber showed (1941, 1942) by comparing the results of its suppression, artificially in Uvularia, and naturally in the Orchidaceae.

Now the symptom of homogeneity in the anther (and also in the testis) is the synchronisation of mitoses within the follicle before meiosis. The symptom of differentiation (or of segregation) is nonsynchronisation, or more precisely, dyschronisation. Thus, when it happens that two dyschronised groups of cells arise before meiosis in the sporogenous tissue of the anther instead of one synchronised group, we have in a simple form the problem of differentiation. Our abnormal sterile clone has produced something more elaborate than arises in the normal development of the anther. This is not entirely novel but the significance of previous instances seems to have been overlooked.

Owing to the habit of studying pollen mother cells and pollen grains in smears we know very little about the positions in the anther of abnormally developing cells. The dwarf pollen grains lie at random in the Tradescantia anther (La Cour, 1949). But we do not know exactly where the embryo-sac-like pollen grains arise in the anthers of Hyacinthus (Stow, 1930).* We observe, however, that our sensitive zones lie in the middle of the anther lobes, in a symmetrical position corresponding to the embryo-sac in an ovule. The same seems to be true of the abnormal cells in Scilla: they are in the "mid-regions of the loculi " (Rees, I952).

So much for analogy. So far as physiological principles are concerned it is clear that homogeneity in a tissue must always depend on free diffusion. Conversely the division of one kind of tissue into

* Stow found that diploid hyacinths (probably "La Victoire") heated to $30^{\circ} \mathrm{C}$. for I 5 hours on 27 th October and kept at $20^{\circ}$ thereafter gave on 12 th December together with 90 per cent. dead pollen grains a proportion of giant pollen grains with 8 , and also 4 and 16 nuclei corresponding to the chief types of Angiosperm embryo-sac. These dry up and die as the anther ripens. 
two kinds must always depend on the creation of a barrier to diffusion between them. In most flowering plants such a barrier arises later around every pollen grain. But it may come too late as in the Orchidaceous types of development described by Barber (1942). In Scilla, in Chrysanthemum, in our clone of Allium, and perhaps in other forms of male sterility, we may say that it comes too early.

The strength of the barriers to diffusion which will be effective should vary with the structure or function of the particles diffusing. In Uvularia and the orchids we indeed find that pollen grain walls are necessary to separate the cells physiologically and cause those which are genetically defective to lag in development. But in a case in Tradescantia (Haque, I953), apparently as a result of a genetic difference, dyschrony sets in between nuclei in the same pollen grain. Here the effective or discriminate particle can have been stopped by no obstacle but the nuclear membrane itself.

Thus we have the nuclear barrier in Tradescantia, the absence of cell barriers after meiosis in orchids, and the premature creation of cell barriers before meiosis in the abnormal Allium or Scilla, all constituting exceptions which prove and define the ordinary and highly adaptive rule of development. This rule may now be stated as follows :

(i) No differentiation arises in the sporogenous tissue.

(ii) Effective barriers between cells arise after meiosis.

(iii) They make it possible for the genetically distinct products of meiosis to be separately tested in respect of their capacities for growth before they are committed to, and protected by, fertilisation.

\section{THE BREAKAGE-ASYNAPSIS SYNDROME}

The abnormal characteristics of our clone of Allium cepa are evidently genetically determined since they distinguish it from the normal in successive years and in different countries. The nucleolar microcytes and the polyploid cells were apparently independent in their origin of the main correlated or concurrent group of abnormalities. This group differs from the classical instance described by Beadle in maize in three respects :

(i) The sporogenous tissue is differentiated, as we have seen, into sensitive and non-sensitive zones in respect of breakdown before meiosis.

(ii) The sensitive zones reveal their defect in successive stages and doubtless early, or late, or not at all, subject presumably to conditions external to the tissue.

(iii) The defect reveals itself also as a group of errors delaying the onset of mitosis or meiosis, prolonging the growth of the cell, and upsetting the continuity or reproduction and pairing of the chromosomes. 
Such a group of correlated abnormalities we may call a breakageasynapsis syndrome, but it is, of course, a part of the larger syndrome which later brings atrophy to all the pollen grains after their mitosis.

In its general character our abnormality resembles that found by Rees in Scilla. It even shows the same preponderance of sister reunions after breakage at meiosis. The only differences are, first, that our asynaptic cells do not all show breakage so that we are able to separate the two errors. And, secondly, owing to the abundance of the Allium flowers, we are able to follow our abnormality back in development to an earlier stage and see its origin in two steps.

Both the Scilla and the Allium abnormalities agree with that found by Dowrick in Chrysanthemum in showing a correlation of enlarged cells and delayed prophase of meiosis with a reduced frequency of chiasma formation. In all three cases, but sharpest in Scilla and Allium, it is the differentiation of two types of mother cell in the same anther which makes it possible to demonstrate this multiple correlation.

The primary characteristic of the breakage-asynapsis syndrome is a delay in the onset of prophase of the pre-meiotic mitosis. This is followed by a corresponding delay in the later stages of this mitosis. But when it affects meiosis itself the delay is reduced by the time first metaphase is reached: the delayed cells partly catch up the normal ones. This principle of convergence in cell development was first inferred in X-ray experiments on pollen and was assumed to be due to diffusion of mitosis-promoting materials which would favour synchronisation (Darlington and La Cour, 1945, graph II). The delay in the beginning of prophase is used, we must however suppose, in growth since the delayed cells are always larger than the normal ones. Evidently, therefore, the ordinary prophase represents a switch from processes of growth to processes of transformation, reconstruction and movement (fig. 2).

The suggestion that the beginning of prophase goes with a radical change, a switch, in cell metabolism rests here on an entirely new kind of evidence. But it is related to the evidence of Lettré (I950) and later of Stich (1954) that prophase is initiated by a change from aerobic to anaerobic respiration. Whatever the nature of the change, however, the organisation of mitosis or meiosis must represent a dissipation of energy and a loss of materials which would arrest or diminish any process of growth.

The secondary characteristic of the syndrome is its effect on pairing at meiosis. A postponement of prophase reverses the normal advancement of prophase which distinguishes meiosis from mitosis. It is natural therefore that it should counteract or undo some of the properties of meiosis. This it evidently does when it inhibits chiasma formation and metaphase pairing, producing " asynapsis".

The habit by which the abnormalities affect only a part of the cells and these only in a succession of stages points, as we have argued, to a divergence of two types of cells following normal and abnormal 
channels of development. It seems that the abnormality diverges to reach a threshold for breakage at different stages in the development of the pollen mother cell precursors. It also seems that the threshold for asynapsis is lower than for breakage since all delayed cells are asynaptic but not all asynaptic cells show breakage.

Several problems remain to be considered. The postponed prophase does not stop pachytene pairing which seems to be complete. It does not even prevent the chromosomes at pachytene developing

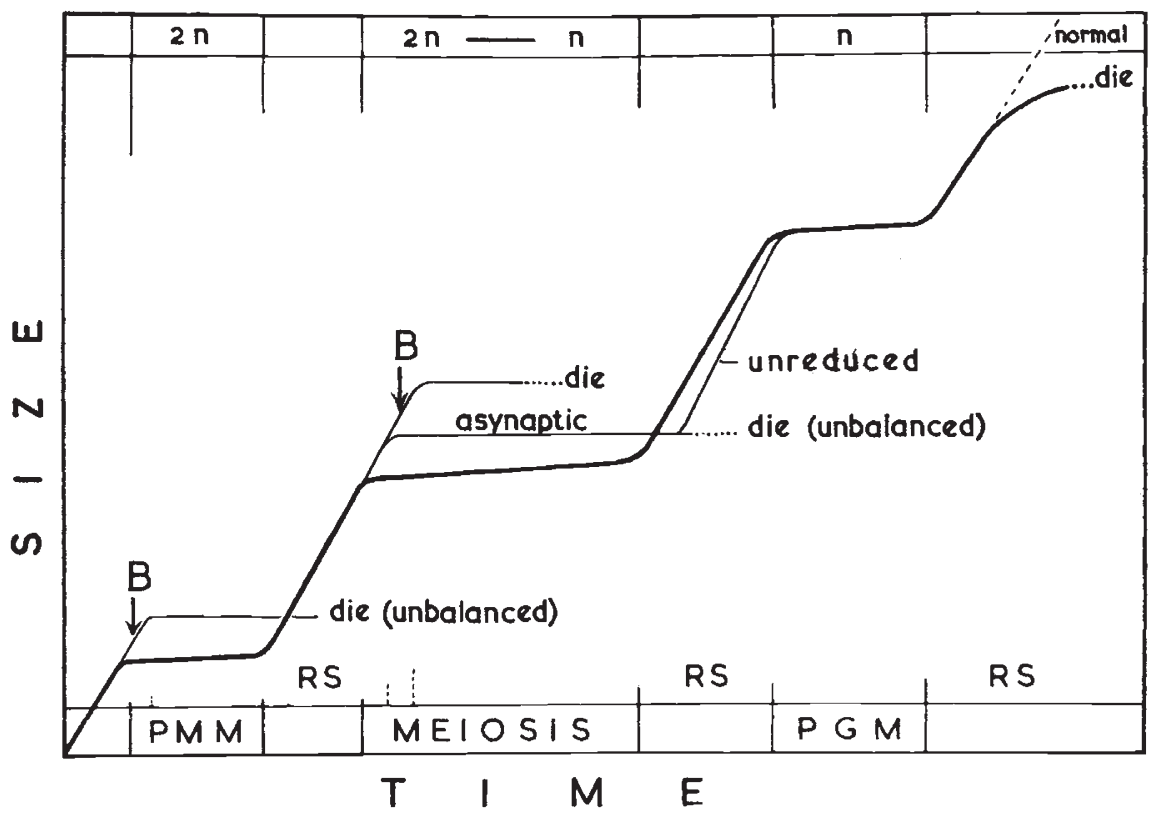

FIG. 2.-Graph showing the apparent relationships of growth of the male-sterile clone with stage of mitotic development in the general sporogenous tissue (thick line) in the anthers and in the sensitive zones as they become delayed and susceptible to breakage and asynapsis (thin lines). The death of all pollen grains is shown stopping growth in contrast to the development in the anthers of a normal plant.

a coiling which indeed survives at diplotene. It merely reduces the sequel of pairing and coiling, which is chiasma formation, to a very small fraction, less than one-tenth, of normal.

How are we to understand this? Clearly it is not that the chromosomes have become resistant to the breakage involved in crossing over since a proportion of them actually show spontaneous breakage. Rather it would appear that the coiling fails to reach the threshold torsion for crossing over. Observations of diplotene in normal meiosis generally suggest that only about half the coiling is used up in crossing over. A reduction of coiling to about one half such as might follow a delay in pairing would then give the typical asynaptic situation in which cells show a statistically normal curve of chiasma frequency but one in which the modal frequency has fallen to zero. 
The study of the whole development of other types of abnormal anther in its spatial relations would no doubt reveal significant evidence on the physiological questions we have discussed.

\section{SUMMARY}

I. In the anthers of a male-sterile clone of Allium ascalonicum central zones of cells suffer a delay in the onset of mitosis or meiosis relative to the main body of cells.

2. The delayed prophase is correlated with three other effects :-

(i) Continued growth : thus the initiation of mitosis or meiosis represents a switch in cell metabolism, a diversion of energy from growth to reconstruction.

(ii) Chromosome breakage.

(iii) At meiosis, owing to failure of chiasma-formation, asynapsis even more regularly than breakage: thus a delay in prophase undoes the character of meiosis.

3. The undelayed cell development in the anther entails three successive and apparently unrelated errors :-

(i) Errors of spindle development lead to polyploid mother cells and pollen grains.

(ii) Nucleolar chromosomes show a special frequency of failure of chiasma-formation and form microcytes. These are capable of a synchronised second division.

(iii) All pollen grains shrivel and die after their first mitosis.

4. The whole syndrome of effects ( $c f$. fig. 2) may be represented as follows :-

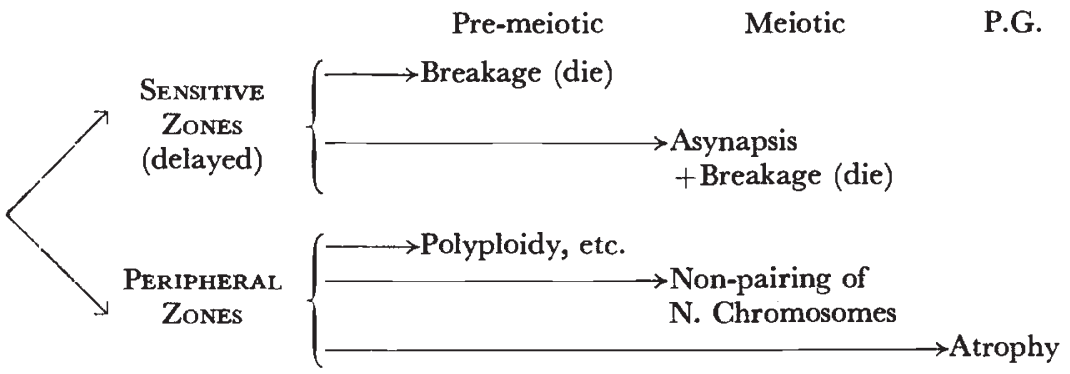

\section{REFERENCES}

barber, H. N. I941. Chromosome behaviour in Uvularia. 7. Genet., 42, 223-257. BARBER, H. N. 1942. The pollen grain division in the Orchidacex. F. Genet., 43, 97-103.

BEADLE, G. W. 1933. Further studies in asynaptic maize. Cytologia, 4, 269-287.

BEADLE, G. W., AND MCcLInTOCK, B. 1928. A genic disturbance of meiosis in Zea mays. Science, 68,433 .

Darlington, G. D. 1929. Meiosis in polyploids. II. Aneuploid Hyacinths. $\mathcal{F}$. Genet., 21, 17-56. 


\section{Plate I}

FIG. I.-Metaphase from the root tip meristem $(2 n=\mathrm{I} 6) . \quad \times$ I I 70 .

FIG. 2.-L.S. through anther. Most of the cells have completed the premeiotic mitosis and are at premeiotic resting stage. A group of delayed and broken cells are seen undergoing premeiotic mitosis. $\times 240$.

FIG. 3.-Three cells at pachytene : one tetraploid, one diploid and one with two diploid nuclei. $\times 600$.

Fig. 4.-Early diplotene in an asynaptic cell. The points where the homologous chromosomes cross each other are merely coils. A few positions where the chromosomes have undergone breakage can be seen. $\times$ i i jo.

FIG. 5.-Diakinesis in an asynaptic cell with heavily broken chromosomes. The fragments are held to their counterparts by stickiness. $\times$ I I 70 .

Fig. 6.-Early first anaphase in an asynaptic cell. All the 16 univalents are arranged on the equator and are dividing mitotically. $\times 1170$.

FIG. 7.- Ist metaphase in an asynaptic cell with heavy chromosome breakage. $\times$ I 170 .

FIG. 8.-A patch of normal ist metaphase cells surrounding a delayed, large, asynaptic and broken cell at diakinesis. $\times 900$. 


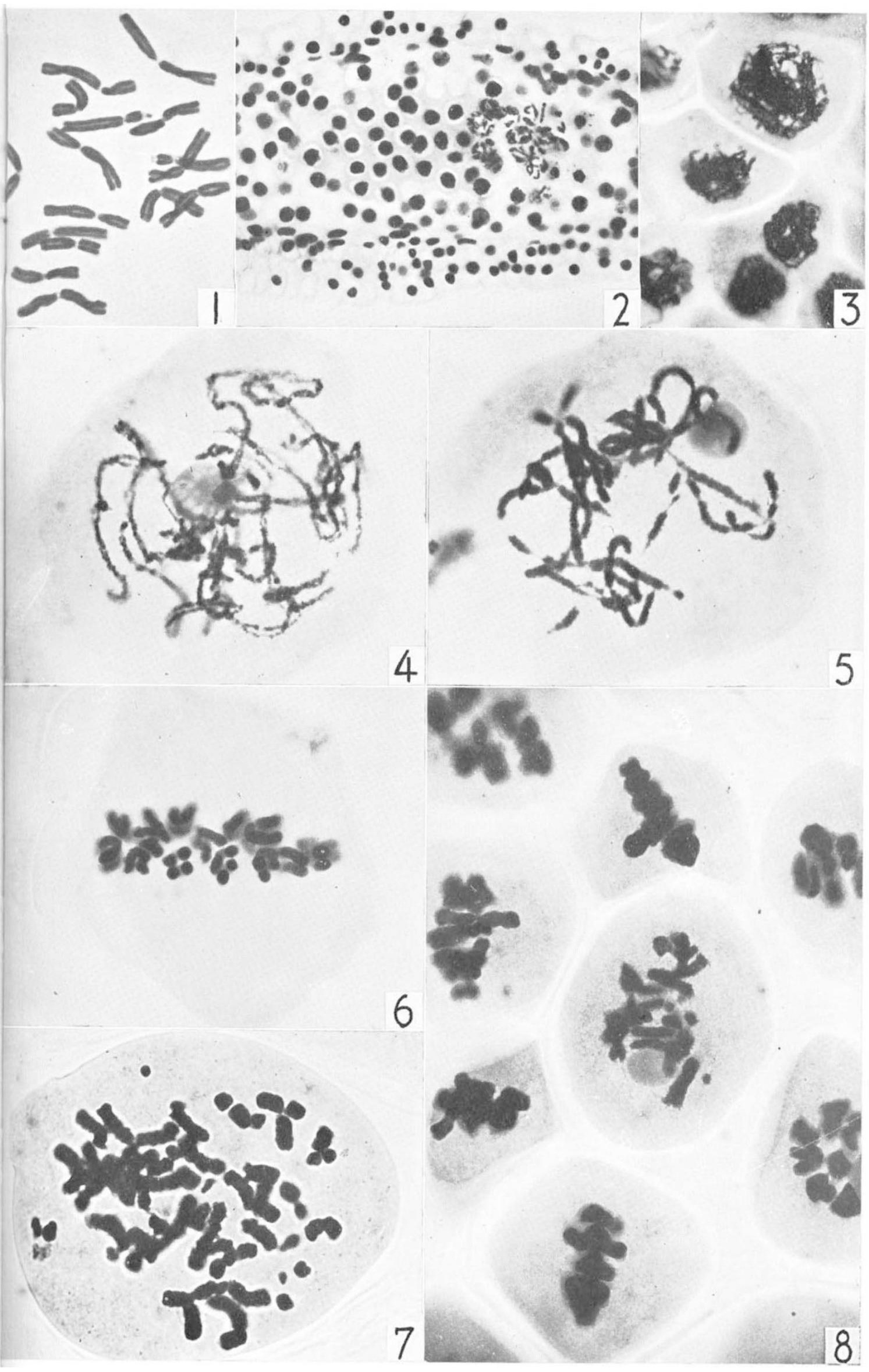


FIG. 9.- Ist anaphase in an asynaptic cell. Sister reunion following chromosome breakage has led to seven bridges (two out of focus) and many acentrics. $\times$ I 170 .

FIG. 10.-Ist meta-anaphase in an asynaptic cell with sticky and highly despiralised chromosomes. $X$ I I 70 .

FIG. I I.-2nd metaphase. Sister cells of the dyad each with 16 chromosomes instead of the normal eight. $\times$ I I 70 .

FIG. 1 2.-2nd anaphase. Each sister cell of the dyad has seven chromosomes. The remaining two chromosomes are present in two microcytes at the equator of the first division and are synchronised with the two major cells. X I I 7o.

FIGs. I 3 and 14.-Tetrads with one and two microcytes respectively. $\times 840$.

FIG. I5.-Tetrad with two microcytes, each having two small nuclei. This condition results from the situation illustrated in fig. 13. The two inactive micro-nuclei are the result of breakage during meiosis ; they represent fragments. $\times 840$.

FIGS. I6-18.- - Ist mitoses in pollen grains following chromosome breakage at meiosis.

FIG. 16.-Metaphase showing an acentric fragment at 2 o'clock and a minute fragment at 6 o'clock. $\times 1635$.

FIG. 17.-Metaphase showing a dicentric chromosome at 7 o'clock and a large acentric fragment at 4 o'clock : there are eight chromosomes and eight centromeres. $\times 1635$.

FIG. 18.-A pollen grain with a large number of micro-nuclei. $\times 1635$. 
DARLington, C. D. I935. The internal mechanics of the chromosomes. II. P.R.S. $\mathrm{B}, I I 8,59-73$.

DARLington, C. D. I937. Recent Advances in Cytology. London : Ghurchill.

DARLington, C. D., AND LA COUR, L. F. 1945. Chromosome breakage and the nucleic acid cycle. 7. Genet., 46, I 80-267.

HaQUe, A. 1952. The irradiation of meiosis in Tradescantia. Heredity, 6, Suppl. $57-75$.

HAQUE, A. 1953. Non-synchronised mitosis in a common cytoplasm. Heredity, $7,429-43 \mathrm{I}$.

LA COUR, L. F. 1947. Improvements in plant cytological technique. II. Bot. Rev., I3, $216-240$.

LA COUR, L. F. I949. Nuclear differentiation in the pollen grain. Heredity, 3, 319-337.

LetTRÉ, hans. I950. Neuere Ergebnisse der Chemie der Kern- und Zellteilung, Zb. f. Gynäk., 72, 1851-186o.

LEVAN, A. 1940. The cytology of Allium amplectens and the occurrence in nature of its asynapsis. Hereditas, 26, 353-394.

мcclintock, в. I934. The development of the nucleoli in Zea mays. Zts. Zf. u. mik. Anat., 2I, 294-328.

MCLEISH, J. I 954 . The consequences of localised chromosome breakage. Heredity, $8,3^{85}-408$.

REES, H. 1952. Asynapsis and spontaneous chromosome breakage in Scilla. Heredity, 6, 89-97.

sтich, H. I954. Der Einfluss von Giften auf die zur Meiose führenden Stoffwechselvorgänge bei Sabellaria spinulosa. Experientia, Io, I84.

srow, I. 1930. Embryo-sac-like giant pollen grains in the anther of Hyacinthus orientalis. Cytologia, 1,4 I 7-439. 